\title{
Estimation of Genetic and Crossbreeding Parameters for Birth Weight in Baladi Cattle and their Crosses with Abondance and Tarentaise Breeds in Egypt Hanaa Abdelharith \\ Animal Production Research Institute, Agricultural Research Center, Dokki, Giza, Egypt.
}

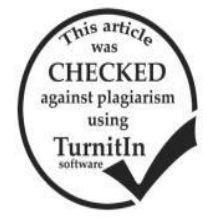

\begin{abstract}
Genetic and crossbreeding parameters for birth weight (BWT) were estimated in pure Baladi (BB), Abondance (AB) with BB crossbred and Tarentaise (TR) with BB crossbred calves. Data were collected from breeders in two governorates and from Sids Experimental Farm belonging to Animal Production Research Institute. Data included 9334 records of calves born for 174 sires and 5182 dams. Data consisted of seven genotypes; $\mathrm{BB}, 1 / 2 \mathrm{AB} / \mathrm{TR} 1 / 2 \mathrm{BB}, 3 / 4 \mathrm{AB} / \mathrm{TR} 1 / 4 \mathrm{BB}$ and $7 / 8 \mathrm{AB} / \mathrm{TR} 1 / 8 \mathrm{BB}$. Group differences were highly significant, $(\mathrm{P}<0.0001)$. Least squares means of $\mathrm{BWT}$ were $22.3,32.4,32.4$ and $32.6 \mathrm{~kg}$ for $\mathrm{BB}, 1 / 2 \mathrm{AB}, 3 / 4 \mathrm{AB}$ and $7 / 8 \mathrm{AB}$, respectively and were $32.0,32.0$ and $31.9 \mathrm{~kg}$ for $1 / 2 \mathrm{TR}, 3 / 4 \mathrm{TR}$ and $7 / 8 \mathrm{TR}$, respectively. Individual and maternal additive and maternal heterosis effects were studied, variance components and heritability estimates were estimated. The individual additive effects of $\mathrm{AB}$ and TR for BWT were significant being $-9.98 \mathrm{~kg}$ and $-9.43 \mathrm{~kg}$, respectively. Maternal additive effects were significant and positive being $4.86 \mathrm{~kg}$ and $4.81 \mathrm{~kg}$ for $\mathrm{AB}$ and $\mathrm{TR}$, respectively. Maternal heterosis estimates were non-significant with small magnitude and was negative for $\mathrm{AB}$ crossbreds $(-0.06 \mathrm{~kg}$ ) and was positive for TR crossbreds $(0.12 \mathrm{~kg})$. Heritability estimates for BWT were $0.16,0.51$ and 0.55 for $\mathrm{BB}, \mathrm{AB}$ crossbreds and TR crossbreds, respectively. In general, Crossbred calves of AB or TR were higher in BWT than pure $\mathrm{BB}$ calves. Individual additive effects show an advantage for $\mathrm{AB}$ and TR crossbreds, while maternal additive effects expressed the superiority of the BB dams over the crossbred dams. Results reveal that genetic improvement of BWT in BB could be achieved by crossing with $\mathrm{AB}$ or TR breeds for higher BWT.
\end{abstract}

Keywords: Baladi cattle, Abondance, Tarentaise, crossbreeding, birth weight and genetic parameters.

\section{INTRODUCTION}

The introduction of European dual-purpose breeds could improve calf birth weight and productivity of local cattle. Favourable effects of crossing cattle are heterosis effects and the additive differences between breeds. Several studies have indicated the advantages of crosses between local cattle (Baladi) and European breeds in several aspects. (Mostageer et al., 1987; Arafa, 1996; Afifi et al., 1996; Nasr et al., 1997 and Ibrahim et al., 2005). The advantage of crossbred animals over the pure bred animals is the exhibit of heterosis or hybrid vigor. So, crossbred animals are expected to have greater performance than the pure local cattle. Generally, the level of heterosis is higher under poor environmental conditions than under good environmental conditions, (Skrypzeck et al., 2000). Leal and MacNeil (2018) reported that crossbred animals grow more rapidly and well adapted mostly when the parental breeds are genetically distant. This better performance occurs due to combining additive breed effects and heterosis.

The weight of the newly born calf is of great importance to the producer. Selvan et al. (2018) reported that because birth weight of calves is easily measured and correlated with other performance traits, it should be considered in the genetic improvement programs.

Differences in breed additive and heterosis effects help to explain the differences in the animal performance, Leal and MacNeil (2018). Information about the genetic parameters and differences between breeds are essential to evaluate the suitability of breeds for crossbreeding, (Brandt et al., 2010). The estimation of the crossbreeding parameters is affected by type, numbers and by the estimability problems of genetic groups included in the crossbreeding experiment, (Lema et al., 2011).

Estimates of variance components and genetic parameters for birth weight of crossbred data have been reported in many studies, (Mourão et al., 2007; Haile et al., 2011; Chen et al., 2012; Vega-Murillo et al., 2012 and Selvan et al., 2018).

Previous research work on the experimental herd of the Animal Production Research Institute (APRI) crossbred animals of $\mathrm{AB}$ and $\mathrm{TR}$ breeds with pure $\mathrm{BB}$ covered the differences between the genetic groups in some productive traits, blood and milk parameters and final weights with carcass traits, (Ibrahim et al., 2005; Abdelharith, 2009 and Tawfik, 2010). The authors concluded better average daily gain, feed conversion rate, dressing-out percentages, higher birth weight and higher milk yield of crossbred animals than BB.

The objective of this study was to estimate genetic and crossbreeding parameters for birth weight in Egyptian Baladi crossbreds with French breeds Abondance and Tarentaise.

\section{MATERIALS AND METHODS}

\section{Data}

Data utilized in this study were collected from 2250 breeders at two governorates and from Sids Experimental Farm belonging to Animal Production Research Institute. Breeders' data of the French Egyptian Program were provided by the General Organisation of Veterinary Service (GOVS). The program started in the year 1996 to improve the milk and meat production of Egyptian Baladi cattle by crossing Baladi cows with two French breeds Abondance (AB) and Tarentaise (TR). These two breeds were selected favouring their colour which resembles Baladi cattle colour beside their great production of milk and meat. Pure Baladi cows $(\mathrm{BB})$ were inseminated by the imported semen of the two French breeds to make $\mathrm{F} 1(1 / 2 \mathrm{AB} / \mathrm{TR} 1 / 2 \mathrm{BB})$ generation, then $\mathrm{F} 2(3 / 4 \mathrm{AB} / \mathrm{TR} \quad 1 / 4 \mathrm{BB}), \mathrm{F} 3(7 / 8 \mathrm{AB} / \mathrm{TR} \quad 1 / 8 \mathrm{BB})$ and $\mathrm{F} 4$ $(15 / 16 \mathrm{AB} / \mathrm{TR} 1 / 16 \mathrm{BB})$. From the third and fourth generations, crossbred bulls have been made to inseminate pure Baladi cows. Data of these crossbred bulls were not included in the analyses and kept only records of pure Baladi crossed by pure French semen. The crossbred trial was applied in two governorates; Fayoum and Bany-Sweif in Mid Egypt. All data collected from this program was only corssbred. No pure Baladi or French calves were available.

At later time, a similar trial was conducted in Sids Experimental Farm, Bany-sweif governorate, APRI, with small numbers of cows which were not enough to make genetic evaluation for the herd. So, crossbred data of GOVS program was utilized, in addition, the pure Baladi data of APRI to form contemporary groups. 
In winter, animals at small holders were fed mainly Egyptian clover (berseem) and in summer some concentrates with corn forages (Darawa) with a period of suckling might expand for six months. Animals were kept in different housing systems according to the breeder's facilities ranging from loose open yards to closed housing with ceiling fans or open shaded.

Total collected data of birth weight were 9334 records born for 174 sires and 5182 dams. Description of data categories in different genetic groups is presented in Table (1).

Table 1. Description of data in the different genetic groups.

\begin{tabular}{lccc}
\hline Genetic group* & Number of calves & Sires & Dams \\
\hline Baladi pure (BB) & 329 & 20 & 123 \\
$1 / 2$ AB 1/2 BB & 3844 & 35 & 2094 \\
$3 / 4$ AB 1/4 BB & 817 & 32 & 425 \\
$7 / 8$ AB 1/8 BB & 134 & 17 & 70 \\
$1 / 2$ TR 1/2 BB & 3468 & 28 & 2088 \\
$3 / 4$ TR 1/4 BB & 653 & 24 & 335 \\
$7 / 8$ TR 1/8 BB & 89 & 18 & 47 \\
\hline Total & 9334 & 174 & 5182 \\
\hline
\end{tabular}

*Sire breed listed first

\section{Crossbreeding genetic parameters}

Crossbreeding genetic parameters were calculated according to Dickerson (1992) through the estimation of the coefficients of the expected contribution of the genetic effects. The Dickerson model equations included all additive and non-additive effects. The parameters of direct individual additive effect (gI), maternal genetic effect (gM), individual heterosis (hI), maternal heterosis (hM), recombination loss effects in the individual (rI) and in the dam (rM) are presented in Table (2).

Table 2. Coefficients of breed effects for the different genetic groups.

\begin{tabular}{|c|c|c|c|c|c|c|}
\hline Genetic group & $g^{I}$ & $\mathbf{g}^{\mathrm{M}}$ & $h^{I}$ & $\mathbf{h}^{\mathbf{M}}$ & $\mathbf{r}^{1}$ & $\mathbf{r}^{\mathrm{M}}$ \\
\hline Baladi pure (BB) & 1.0 & 1.0 & 0 & 0 & 0 & 0 \\
\hline $1 / 2 \mathrm{AB} / \mathrm{TR} \quad 1 / 2 \mathrm{BB}$ & 0 & 1.0 & 1 & 0 & 0 & 0 \\
\hline $3 / 4 \mathrm{AB} / \mathrm{TR} \quad 1 / 4 \mathrm{BB}$ & -0.5 & 0 & 0.5 & 1 & 0.25 & 0 \\
\hline $7 / 8 \mathrm{AB} / \mathrm{TR} \quad 1 / 8 \mathrm{BB}$ & -0.75 & -0.5 & 0.25 & 0.5 & 0.19 & 0.25 \\
\hline \multicolumn{7}{|c|}{$\begin{array}{l}\mathrm{g}^{\mathrm{I}} \text { : individual additive effects, } \mathrm{g}^{\mathrm{M}} \text { : maternal additive effect, } \\
\mathrm{h}^{\mathrm{I}}: \text { individual heterosis, } \mathbf{h}^{\mathrm{M}}: \text { maternal heterosis, } \\
\mathbf{r}^{\mathrm{I}} \text { : individual recombination loss and } \mathbf{r}^{\mathrm{M}}: \text { maternal recombination } \\
\text { loss. Estimates of } \mathrm{g}^{\mathrm{I}} \text { and } \mathrm{g}^{\mathrm{M}} \text { were calculated by subtract the BB } \\
\text { coefficients - French breeds coefficients. }\end{array}$} \\
\hline
\end{tabular}

\section{Statistical Analyses}

Data were grouped in 53 contemporary groups (CG) to include the crossbred data and their contemporary pure bred data of the same years but under different management, (Sids Farm). The groups were clustered by herd, season and year of calf birthdate. Data included two seasons; winter and summer for 14 years data from 1996 to 2009. As data were mainly from the breeders, age of cows or parity number were not available.

\section{Models}

Three models were applied for:

1- Estimation of the least squares means of the different genetic groups (GG) for birth weight (BWT) for the crossbred data where each of the two French breeds was analysed separately with the pure bred data, using PROC MIXED of the Statistical Analysis System (SAS, 2002). The model used was: $y_{i j k l m}=\mu+G_{i}+C G_{j}+S X_{k}+(G G * S X)_{i k}+s_{l}+e_{i j k l m}$

where: $y_{i j k m}$ is the observation of birth weight, $\mu$ is the general mean, (GG) is the fixed effects of GG (4 GG for each of the French breeds with the pure Baladi), (CG) is the CG, (53 CG), $(\mathbf{S X})_{\mathrm{k}}$ is sex of calf $\left(2\right.$; male and female), $(\mathbf{G G} * \mathbf{S X})_{\mathrm{ik}}$ is the interaction between GG and SX, $\mathrm{s}_{1}$ is the random effect of the sire and $e_{i j k m m}$ is the random error term $\left(0, \sigma_{e}^{2}\right)$.

2- Using the same procedure (MIXED), crossbreeding genetic parameters were estimated and suitable estimable contrasts were fitted. From the full model of Dickerson (1992), only three parameters were estimable; $\mathrm{g}^{\mathrm{I}}, \mathrm{g}^{\mathrm{M}}$ and $\mathrm{h}^{\mathrm{M}}$. The model used was :

$\mathbf{y}_{\mathrm{ijklmno}}=\boldsymbol{\mu}+\mathbf{C G}_{\mathrm{i}}+\mathrm{SX}_{\mathrm{j}}+\mathrm{g}_{\mathrm{k}}^{\mathrm{I}}+\mathrm{g}^{\mathrm{M}}{ }_{\mathrm{l}}+\mathrm{h}^{\mathrm{M}}{ }_{\mathrm{m}}+\mathrm{S}_{\mathrm{n}}+\mathrm{e}_{\mathrm{ijklmno}}$

where: $g^{I}{ }_{k}$ is the individual additive effect, $g^{\mathrm{M}}{ }_{1}$ is the maternal additive effect and $\mathbf{h}^{\mathrm{M}}{ }_{\mathrm{m}}$ is the maternal heterosis effect.

The other effects, y, CG, SX, s and e were described in the previous model.

3- Animal model analyses were performed to estimate variance components and genetic parameters for BWT in each breed data separately. Single-trait derivative-free restricted maximum likelihood (DF- REML) with animal model analysis (Boldman et al., 2000) was used to apply the models. The analyses were solved iteratively and were terminated when the change in the variance of the function values (-2 log likelihood) was below $10^{-9}$. The model used was:

$$
\mathbf{y}=\mathbf{X} \boldsymbol{\beta}+\mathbf{Z a}+\mathbf{e}
$$

Where: $y$ is the vector of BWT observation, $\beta$ is the vector of GG, CG and SX effects which previously described, $X$ is the incidence matrix related observations to $\beta, a$ is the vector of animal, $Z$ is the incidence matrix related observations to a and $\mathrm{e}$ is the random error.

\section{RESULTS AND DISCUSSION}

\section{Genetic group performance}

Least squares means of calf BWT in the different genetic groups of $\mathrm{BB}$ and $\mathrm{AB}$ and $\mathrm{TR}$ crossbreds are presented in Table (3). The effects of GG, CG, SX and interaction between GG and SX were highly significant on BWT. In general, BB calves had lower BWT than crossbred calves of $\mathrm{AB}$ or TR breeds. Baladi calves least squares mean was $22.3 \mathrm{~kg}$ while $1 / 2 \mathrm{AB} 1 / 2 \mathrm{BB}, 3 / 4 \mathrm{AB} 1 / 4 \mathrm{BB}$ and $7 / 8 \mathrm{AB} 1 / 8 \mathrm{BB}$ were heavier, $(32.4,32.4$ and $32.6 \mathrm{~kg}$ ), respectively. Male calves were heavier than female calves, especially in the first generation $\mathrm{F} 1$ calves $(1 / 2 \mathrm{AB} / 1 / 2 \mathrm{BB})$, it was the heaviest $(33.1 \mathrm{~kg})$. Abdelharith (2009) reported lower weights for BWT for F1 (1/2AB $1 / 2 \mathrm{BB}),(27.1) \mathrm{kg}$ and it was higher than $\mathrm{BB}$ calf $\mathrm{BWT}$ with significant effects. On other crossing trial, BB cows with Friesian and Shorthorn European breeds, Arafa et al. (2000) reported heavier crossbred calves than the BB calves. The authors reported 26.6, 26.4 and $20.8 \mathrm{~kg}$ for BB calf BWT in crossbreeding trials with Friesian, Shorthorn and Jersey, respectively.

The least squares means of calf BWT in the different genetic groups of TR and BB crossbreds are also shown in Table (3). Almost same trend of results was found as the $\mathrm{AB}$ crossbred genetic groups except for that the interaction between GG and SX was not significant and the genetic group $7 / 8$ TR $1 / 8$ BB was not the heaviest calves. Upgrading BB with TR in APRI trial revealed that male F1 calves were heavier than male $\mathrm{F} 1 \mathrm{AB}$ crossbred calves, 30.0 vs $27.0 \mathrm{~kg}$, respectively, Abdelharith (2009). In general, male calves had higher BWT than female calves and highest weights were in $1 / 2$ TR $1 / 2$ BB and $3 / 4$ TR $1 / 4$ BB genetic groups, $32.6 \mathrm{~kg}$. 
Table 3. Least squares means (LsMeans) \pm standard errors (S.E.) of birth weight (BWT) for Baladi (BB), Abondance (AB) and Tarentaise (TR) genetic groups.

\begin{tabular}{lcc}
\hline Genetic & LsMeans \pm S.E. & LsMeans \pm S.E. \\
group & AB & TR \\
\hline$\mu$ & $31.2 \pm 1.25$ & $30.8 \pm 1.29$ \\
Genetic group (GG) & $(* * *)$ & $(* * *)$ \\
Baladi pure (BB) & $22.3 \pm 0.48$ & $22.5 \pm 0.46$ \\
1/2 French 1/2 BB & $32.4 \pm 0.24$ & $32.0 \pm 0.23$ \\
3/4 French 1/4 BB & $32.4 \pm 0.25$ & $32.0 \pm 0.25$ \\
7/8 French 1/8 BB & $32.6 \pm 0.33$ & $31.9 \pm 0.37$ \\
Calf Sex & $(* * *)$ & $(* * *)$ \\
Male & $30.4 \pm 0.25$ & $30.2 \pm 0.25$ \\
Female & $29.4 \pm 0.24$ & $28.9 \pm 0.24$ \\
GG*Sex & $(* * *)$ & $23.3 \pm 0.54$ \\
Baladi pure (BB) Male & $23.1 \pm 0.55$ & $21.7 \pm 0.55$ \\
Baladi pure (BB) Female & $21.6 \pm 0.57$ & $32.6 \pm 0.24$ \\
1/2 French 1/2 BB Male & $33.1 \pm 0.25$ & $31.3 \pm 0.23$ \\
1/2 French 1/2 BB Female & $31.7 \pm 0.24$ & $32.6 \pm 0.28$ \\
3/4 French 1/4 BB Male & $32.7 \pm 0.28$ & $31.3 \pm 0.26$ \\
3/4 French 1/4 BB Female & $32.1 \pm 0.26$ & $32.4 \pm 0.48$ \\
7/8 French 1/8 BB Male & $32.8 \pm 0.39$ & $31.3 \pm 0.47$ \\
7/8 French 1/8 BB Female & $32.4 \pm 0.41$ &
\end{tabular}

\section{Crossbreeding parameters}

Individual additive effects $\left(\mathbf{g}^{\mathbf{I}}\right)$

Estimates of individual additive genetic effects $\left(\mathrm{g}^{\mathrm{I}}\right)$ for BWT in $\mathrm{AB}$ and TR crossbred calves were expressed as a deviation from the BB breed. The estimates were negative and significant, indicating an advantage for the French breeds $\mathrm{AB}$ and $\mathrm{TR}$ on $\mathrm{BB},(-9.98$ and $-9.43 \mathrm{~kg})$, respectively, Table (4). The $\mathrm{AB}$ crossbreds show higher $\mathrm{g}^{\mathrm{I}}$ estimate than TR. Arafa et al. (2000) in trials of upgrading BB with Friesian and Shorthorn dairy breeds reported negative and significant estimates of $\mathrm{g}^{\mathrm{I}}$ for BWT of calves, (6.42 and -5.95), respectively and also in favour of the European breeds. Davis et al. (1998) in crossing Tarentaise with beef Herford reported negative and significant $\mathrm{g}^{\mathrm{I}}$ estimate (-2.3) in favour of Herford. Depending on breed performance of milk or meat that involved in the crossing trials, estimates of $\mathrm{g}^{\mathrm{I}}$ and significance are differed. As an example, Skrypzeck et al. (2000) in three breed crossbreds (Afrikaner, Simmentalr and Herford), the additive crossbreeding parameters were positive in Simmentaler and negative for Afrikaner and Herford. Leal and MacNeil (2018) had the same conclusion on different breeds.

Maternal additive effects $\left(g^{M}\right)$

Estimates of maternal additive effects $\left(\mathrm{g}^{\mathrm{M}}\right)$ for BWT in AB and TR crossbreds are presented in Table (4). The estimates were positive and highly significant and show an advantage for the BB cows over the crossbred cows. The estimates of $\mathrm{g}^{\mathrm{M}}$ in both $\mathrm{AB}$ and TR crossbred calves were in a close range, 4.86 and $4.81 \mathrm{~kg}$, respectively. In agreement with these results, Arafa et al. (2000) reported positive estimate of $\mathrm{g}^{\mathrm{M}}$ in favour of the BB dams over the Jersy dams but reported negative estimates in favour of Friesian and Shorthorn dams. Davis et al. (1998) reported negative non-significant estimate $(-0.14)$ for $\mathrm{g}^{\mathrm{M}}$ in a crossbred data between Tarentaise and Herford. Maternal heterosis $\left(h^{\mathbf{M}}\right)$

Estimates of $\mathrm{h}^{\mathrm{M}}$ for BWT in crossbred calves are presented in Table (4). Both estimates are non-significant and of small magnitude, (-0.06 and 0.12), respectively. The estimate of $h^{\mathrm{M}}$ of $\mathrm{AB}$ crossbred calves was negative and in favour of the BB dams that could give calves with birth weight slightly heavier than the crossbred $A B$ dams. On the contrary, the estimate of $\mathrm{h}^{\mathrm{M}}$ of crossbred TR calves was positive and had an advantage for the TR crossbred dams that give calves with higher birth weight than the pure BB dams. Arafa et al. (2000) in upgrading BB with three European dairy breeds, Friesian, Shorthorn and Jersy, the estimates of $h^{\mathrm{M}}$ were positive and in favour of the crossbred dams. Positive and significant estimate of $\mathrm{h}^{\mathrm{M}}$ was reported by Davis et al. (1998) in favour of crossbred dams of Tarentaise and Herford breeds. Crossbred dams in crossing native breeds with imported breeds' trials have been reported to produce higher calf birth weight than the native. Positive estimates of $\mathrm{h}^{\mathrm{M}}$ and in favour of the crossbred dams were reported by Haile et al. (2011), Lema et al. (2011) and Leal and MacNeil (2018).

Table 4. Estimates of individual $\left(\mathrm{g}^{\mathrm{I}}\right)$ and maternal $\left(\mathrm{g}^{\mathrm{M}}\right)$ additive effects and maternal heterosis $\left(h^{\mathrm{M}}\right)$ for BWT in Abondance and Tarentaise crossbred calves.

\begin{tabular}{lccc}
\hline Breed Cross & $\mathbf{g}^{\mathbf{I}}(\mathbf{k g})$ & $\mathbf{g}^{\mathbf{M}}(\mathbf{k g})$ & $\left.\mathbf{h}^{\mathbf{M}} \mathbf{( k g}\right)$ \\
\hline \multirow{2}{*}{ Abondance } & $-9.98 \pm 0.52$ & $4.86 \pm 0.36$ & $-0.06 \pm 0.28$ \\
& $(\mathrm{P}<0.0001)$ & $(\mathrm{P}<0.0001)$ & $(\mathrm{P}<0.834)$ \\
\hline \multirow{2}{*}{ Tarentaise } & $-9.43 \pm 0.51$ & $4.81 \pm 0.41$ & $0.12 \pm 0.35$ \\
& $(\mathrm{P}<0.0001)$ & $(\mathrm{P}<0.0001)$ & $(\mathrm{P}<0.730)$ \\
\hline
\end{tabular}

Variance components and heritability estimates

A univariate model was fitted for each breed separately. Variance components of BWT and heritability estimates are presented in Table (5). The heritability estimates of BWT were 0.51 and 0.55 for $\mathrm{AB}$ crossbreds and TR crossbreds, respectively, whereas the heritability estimate for BB was 0.16 . The discrepancies of heritability estimates could be refer to relatively smaller number of data for BB. Also, smaller genetic variation in BB calves accompanied with higher environmental variance could affect the heritability estimate of BB. Previous crossing trials on BB and their crosses with European breeds did not cover the genetic evaluation for multi breed data. In general, estimates of variance components and heritability are within the range of different breeds for BWT trait in the literature. Chen et al. (2012) reported heritability estimate of 0.38 for Chinese Nanyang crossbred data with Italian Piedmontese and Selvan et al. (2018) reported 0.67 in Zebu crossbred with Holstein Friesian. Haile et al. (2011) reported heritability estimate of 0.33 for crossbred Ethiopian Boran with Holstein Friesian.

Table 5. Estimates of genetic variance $\left(\sigma_{\mathrm{a}}^{2}\right)$, environmental variance $\left(\sigma_{\mathrm{e}}^{2}\right)$, phenotypic variance $\left(\sigma_{p}^{2}\right)$ and heritability estimates $\left(h^{2}\right) \pm$ standard error and C.V $(\%)$

\begin{tabular}{lccc} 
& \multicolumn{2}{c}{$\left(\mathbf{h}^{\mathbf{2}}\right) \pm$ standard error and C.V $(\%)$} \\
\hline Item & $\begin{array}{c}\text { Baladi } \\
\text { pure }\end{array}$ & $\begin{array}{c}\text { Abondance } \\
\text { crossbreds }\end{array}$ & $\begin{array}{c}\text { Tarentaise } \\
\text { crossbreds }\end{array}$ \\
\hline $\mathrm{N}$ & 329 & 4795 & 4210 \\
$\sigma_{2}^{2}$ & 2.03 & 3.87 & 5.06 \\
$\sigma_{{ }^{\mathrm{e}}}^{2}$ & 10.49 & 3.74 & 4.15 \\
$\sigma^{2}$ & 12.52 & 7.61 & 9.21 \\
$\mathrm{~h}^{2}$ & $0.16 \pm 0.11$ & $0.51 \pm 0.05$ & $0.55 \pm 0.07$ \\
$\mathrm{C}^{2}$ & $0.84 \pm 0.11$ & $0.49 \pm 0.05$ & $0.45 \pm 0.07$ \\
C.V.\% & 18.97 & 11.69 & 12.08 \\
\hline
\end{tabular}

$\mathrm{C}^{2}$ :environmental proportion and

C.V $(\%)$ : coefficient of variation

\section{CONCLUSION}

Birth weight has been improved by crossing $\mathrm{BB}$ with French breeds $\mathrm{AB}$ and TR due to individual additive effects of both $\mathrm{AB}$ and $\mathrm{TR}$ and the maternal heterosis of TR. Maternal heterosis of $\mathrm{AB}$ did not have any effect on BWT and did not increase the birth weight. Maternal additive effects expressed the superiority of the Egyptian Baladi cows over the crossbred cows which may lead to an increase of 
the calf birth weight. Results reveal that genetic improvement of calf BWT in BB could be achieved by crossing with $\mathrm{AB}$ or TR breeds for higher BWT.

\section{ACKNOWLEDGMENT}

The author would like to thank the GOVS for providing data of crossbred calves.

\section{REFERENCES}

Abdelharith, Hanaa. 2009. Comparison between Baladi Cattle and their F1 Crossbreds with French Abondance and Tarentaise Breeds in Some Performance Traits. Egypt. J. Basic and Appl Physiol. 8(1):17-32.

Afifi, E.A., MF. Abdel-Glil and S.A. Arafa. 1996. Effect of crossing and grading Domiati cattle with two European breeds in Egypt. Annals Agric. Sci. Moshtohor, Egypt. 34(4):1517-1535.

Arafa, S.A. 1996. Genetic analysis for some productive traits in purebred and graded dairy cattle under the Egyptian conditions. Ph.D. Thesis, Faculty of Agriculture, Zagazig University, Banha Branch

Arafa, S. A.; E.A.Afifi; M.H. Khalil and H.M. Ali. 2000 Heterotic components for birth weight in three upgrading trials of dairy cattle raised in Egypt. Proc. $3^{\text {rd }}$ All Africa Conf. Anim. Agric. \& $11^{\text {th }}$ Conf. Egyptian Soc. Anim. Prod. Alexandria, Egypt, 6-9 November 2000:81-86.

Boldman, K.G., L.A. kriese, L.D.Van Vleck, C.P Van Tassell and S.D. Kachman. 2000. A set of programs to obtain estimates of variance and covariance. U.S. department of Agriculture, Agricultural Research Services (last revised 31/8/2000).

Brandt,H., A. Mullenhoff,, C. Lambertz, G. Erhardt, and M. Gauly. 2010. Estimation of genetic and crossbreeding parameters for preweaning traits in German Angus and Simmental beef cattle and the reciprocal crosses. J. Anim. Sci. 2010. 88:80-86.

Chen, J., H.B. Zhu, D. Wang, H.S. Hao, W.H. Du and X.M. Zhao. 2012. Estimation of genetic parameters for growth traits in a crossbred population derived from Piedmontese and

Nanyang cattle using a multi-trait animal model. J. Animal and Vet. Advances. 11(10):1570-1573.

Davis, K.C., D. D. Kress, D. E. Doornbos and D. C. Anderson. 1998. Heterosis and breed additive effects for Hereford, Tarentaise, and the reciprocal crosses for calf traits. J. Anim. Sci. 76:701-705.

Dickerson, G.E. 1992. Manual for evaluation of breeds and crosses of domestic animals. FAO, Rome.

Haile, A., B.K. Joshi, W. Ayalew, A. Tegegne and A. Singh. 2011. Genetic evaluation of Ethiopian Boran cattle and their crosses with Holstein Friesian for growth performance in central Ethiopia. J. Anim. Breed. Genet. 128: 133-140.
Ibrahim, S.; M. El-Gaafarawy; S.M. El-Sheikh; H.A. ElKousy and S.A. Swiefy. 2005. Feeding and meat production-related parameters in Baladi, Abondance $\mathrm{x}$ Baladi and Tarentaise $\mathrm{x}$ Baladi fattened calves. Proceedings of the second conference of the Anim. Produc. Res. Instit. \& Regional Symposium on Buffalo Produc., 27-29 September, 2005, Sakha, Kafr El-Sheikh, Egypt.pp. 107-118

Leal, W.S. and M. D. MacNeil. 2018. Direct and maternal breed additive and heterosis effects on growth traits of beef cattle raised in southern Brazil. J. Anim. Sci. 96:2536-2544.

Lema, O.M., D. Gimeno , N.J.L. Dionello and E.A. Navajas. 2011. Pre-weaning performance of Hereford, Angus, Salers and Nellore crossbred calves: Individual and maternal additive and non-additive effects. Livestock Science 142: 288-297.

Mostageer, A.; Y.A. Afifi; M.A Morsy and A.A. Nigm. 1987: Grading up Baladi cattle with Friesians in Egypt. J. Anim. Breed. Genet. 104(5):383-390.

Mourão, G.B., J.B.S. Ferraz, J.P. Eler, J.C.C. Balieiro, R.S Bueno, E.C. Mattos and L.G.G. Figueiredo. 2007. Genetic parameters for growth traits of a Brazilian Bos taurus x Bos indicus beef composite. Genetics and Molecular Research 6 (4): 1190-1200.

Nasr, A.S.; E.I. Abou-Fandoud and I.F.M. Marai. 1997: Evaluation of grading up native cattle with Friesian or Brown Swiss, under Egyptian desert conditions. International Conf. on Animal Production, Poultry and Rabbit Production, Sept., 2-4, pp.213-225, Cairo, Egypt.

SAS, 2002. User's guide. 9.00 edn, Statistical Analysis System Institute Inc. Cary, U.S.A

Selvan, A., Tantia, M., Kumaresan, A., Kumar, A., Kumar, D., Karuthadurai, T., and A. Upadhyay, 2018. Phenotypic and Genetic Parameters Estimation for Birth Weight in Zebu and Crossbred Calves Born Under Organized Farm Conditions in India. International Journal of Livestock Research, 8(6), 4858.

Skrypzeck, H., S.J. Schoeman, G.F. Jordaan1 and F.W.C. Neser. 2000. Estimates of crossbreeding parameters in a multibreed beef cattle crossbreeding Project. South African Journal of Animal Science. 30(3):193203.

Tawfik, Nagwa. 2010. A comparative study on mammary gland activity in Baladi cows and their crosses with French abundance and Tarentaise cows. Ph.D. Thesis, Faculty of Agriculture, Cairo University, Egypt.

Vega-Murillo, V.E. and A. Rios-Utrera. 2012. Multiplebreed genetic evaluation of growth traits in Simmental and Simbrah cattle. Tropical and Subtropical Agroecosystems. 15:403-414.

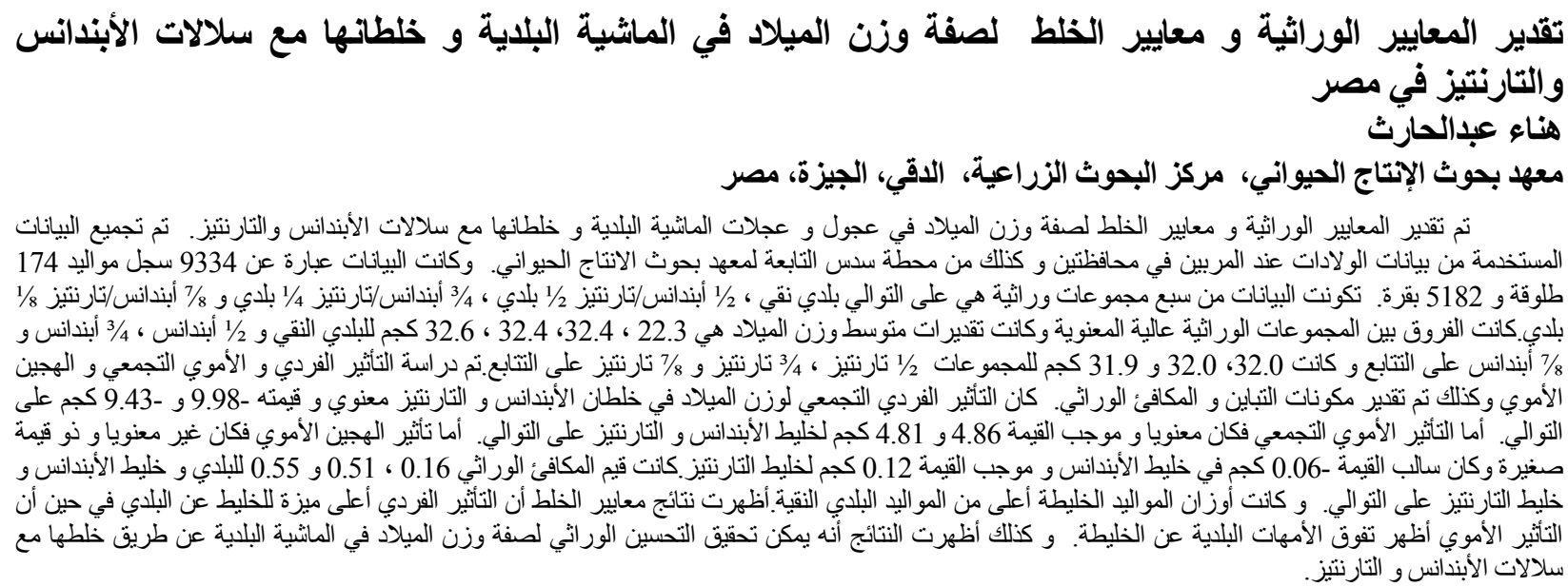

